\title{
Recognizing the sex of a walker from a dynamic point-light display
}

\author{
LYNN T. KOZLOWSKI and JAMES E. CUTTING \\ Wesleyan University, Middletown, Connecticut 06457
}

\begin{abstract}
The sex of human walkers can be recognized without familiarity cues from displays of pointlight sources mounted on major joints. Static versions of these abstract displays do not permit accurate recognition of sex. Variation in the degree of armswing or in walking speed generally interferes with recognition, except that faster speeds are associated somewhat with improved recognition of females. Lights on upper-body joints permit more accurate guesses than do lights on lower-body joints, but identification is possible even from minimal displays, with lights placed only on the ankles. No feedback was given to observers. Confidence judgments of sex relate to the accuracy of responses in a manner that suggests that viewers know what they are doing.
\end{abstract}

The present set of experiments was prompted by two films by Gunnar Johansson (Maas \& Johansson, 1971a, 1971b). Point-light sources are attached to the joints of a person and the surround darkened. When the individual walks, runs, rides a bicycle, or does pushups, only an array of correlated movements among lights can be seen. What is seen, however, is not what is experienced. There is absolutely no doubt that this conflation of lights is a human being.

Johansson has explored the general aspects of this technique (Johansson, 1973), has emphasized its significance for any theory of visual perception (Johansson, 1974, 1975), and has begun to write a calculus for biological motion perception (Johansson, $1973,1976)$. We, on the other hand, have become interested in the phenomenon itself. We have shown that an array of dynamic point-lights mounted on a walker is sufficient for recognizing and identifying oneself and one's friends (Cutting \& Kozlowski, 1977). Provoked by the success of that demonstration, we looked for more general aspects of recognition. One question on a study guide circulated with Johansson's films interested us: Is it possible to recognize the sex of a walker from these dynamic displays? By asking the question, Maas and Johnsson imply that it is. We sought to confirm their suspicion, to determine to what degree such recognition occurs, and to explore some of the parameters of sex recognition without familiarity cues.

This research was sponsored by research grants from Wesleyan University to both authors. We thank Robert J. White for technical assistance, Deborah $\mathrm{A}$. Cassidy for assistance in running experiments, and Catharine D. Barclay and Kendall J. Bryant for assistance in statistical analysis. James E. Cutting is also a member of the Haskins Laboratories. Requests for reprints should be sent to L. T. Kozlowski, Department of Psychology, Wesleyan University, Middletown, Connecticut 06457.

\section{EXPERIMENT 1: DYNAMIC DISPLAYS}

\section{Method}

We employed the second of Johansson's (1973) techniques: glassbead retroreflective tape wrapped around joints, videotape recording equipment, and bright lights focused on the walking area and mounted very close to the lens of a television camera. The contrast of the resulting image on the television monitor is turned to maximum, and the brightness to minimum so that only the reflectant patches are seen.

Six Wesleyan University undergraduates, three males and three females, served as walkers. Each had a normal gait. All were approximately the same height $(1.63$ to $1.73 \mathrm{~m})$ and weight (55 to $68 \mathrm{~kg}$ ). All wore blue jeans and a dark turtleneck shirt during the recording session. Five-centimeter-wide commercially available reflectant tape was wrapped around their wrists, around their arms just above the elbow, around their ankles, and around their legs just above the knee. Patches of tape, $5 \times 15 \mathrm{~cm}$, were attached to their belts at the hips and to their shoulders as epaulets, half on the shoulder and half on the upper arm. Each walked at his or her own pace for several minutes until we were satisfied that he or she was not "performing" before the camera. We videotaped side views of the individuals as they walked in a straight line in front of the camera, about $8 \mathrm{~m}$ from the lens at the closest point. Each walked back and forth 10 times. Both head and feet were well within the pictured frame. There was no reflectant tape on the head. Each walker was on camera for five strides $( \pm 1 / 4$ stride) for each pass across the viewing field. The camera was fixed in position and did not pan to follow the walker. Walkers were videotaped individually.

Presentation order of all 60 tokens (6 walkers, 10 times each) was randomized by recording onto a second videotape. The dubbing procedure involved two helical-scan videotape recorders, a monitor connected to one recorder on which the source tape was played, and a television camera focused on the monitor and connected to the second tape recorder, on which the test tape was recorded. Test trials were recorded by locating the particular trial to be dubbed from the source tape (a process aided by an audio channel recorded onto it after the recording session), playing that trial on the source videotape recorder and recording it on the other. This sequence was repeated until all trials were recorded, Each trial consisted of the individual walking across the screen from left to right, a brief pause of 3 to $5 \mathrm{sec}$, and then the same individual walking from right to left. An interval of 15 to $20 \mathrm{sec}$ 
occurred between trials to insure that both video recorders reached the same speed and that no "flop-over" of image on the monitor occurred within a trial. This same video tape sequence was used by Cutting and Kozlowski (1977).

The videotape dubbing procedure degraded the stimuli somewhat, but to our advantage. The point-lights "bloomed"' slightly, becoming larger and more circular. Static approximations to our dynamic stimuli can be seen in Figure 1. Each of the six walkers is portrayed in a cluster of four point-light configurations. Those on the top of each cluster show the individual walking from left to right, those on the bottom from right to left. The two configurations on the left of each of the clusters portray the walker at a time when arms and legs are most outstretched, and those to the right at a time when the body is most aligned, on one stiff leg with the other knee slightly raised. Walkers 1,2 , and 3 are females; 4, 5, and 6 are males.

Thirty Wesleyan University undergraduates, 15 males and 15 females, were paid to view the test sequence. They sat 2 to $4 \mathrm{~m}$ from the monitor in groups of six or less. For each trial they wrote down $\mathrm{M}$ or $\mathrm{F}$ to indicate the sex of the walker, and used a 5-point unipolar scale to indicate confidence in their judgments. Visual angle, measured vertically, was between about $2^{\circ}$ and $4^{\circ}$ for each viewer.

\section{Results and Discussion}

As shown in Table 1 , Walkers 4,5 , and 6 were correctly identified as male on an average of $72 \%$ of all trials, and Walkers 2 and 3 were correctly identified as female on $67 \%$ of all trials. Walker 1 , however, proved to be an anomaly: She was identified as female only $32 \%$ of all trials, a result of the same magnitude as the others but in the wrong direction. This fact is considered in more depth in Experiments 3, 4, and 5. There was no effect of the sex of the viewer in this or in any other experiment in this paper.

Figure 2 shows the mean percent correct identification as a function of the raters' confidence in their guesses. The anomalous walker is omitted from the data, in order to indicate the confidence effect more

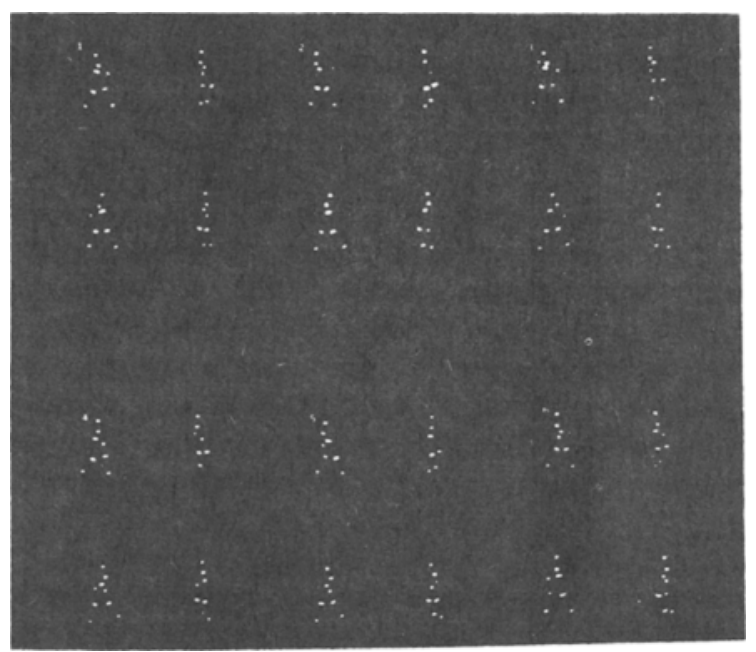

Figure 1. Static approximations of the dynamic stimuli for the six walkers.
Table 1

Percent Correct Identification of Sex for Each of the Six Walkers in Experiments 1 and 2

\begin{tabular}{|c|c|c|c|c|c|c|c|}
\hline & \multicolumn{3}{|c|}{$\begin{array}{l}\text { Female } \\
\text { Walkers }\end{array}$} & \multicolumn{3}{|c|}{$\begin{array}{c}\text { Male } \\
\text { Walkers }\end{array}$} & \multirow[b]{2}{*}{ Mean } \\
\hline & 1 & 2 & 3 & 4 & 5 & 6 & \\
\hline $\begin{array}{l}\text { Dynamic Displays } \\
\text { (Experiment 1) }\end{array}$ & $32 *$ & $67^{*}$ & $64 *$ & $62 *$ & $73^{*}$ & $81^{*}$ & $63^{*}$ \\
\hline $\begin{array}{l}\text { Static Displays } \\
\text { (Experiment 2) }\end{array}$ & 41 & 50 & 50 & 49 & $40^{*}+$ & 46 & 46 \\
\hline
\end{tabular}

${ }^{*} p<.05$ by two-tailed $t$ tests.

fThese results are significant in the opposite direction.

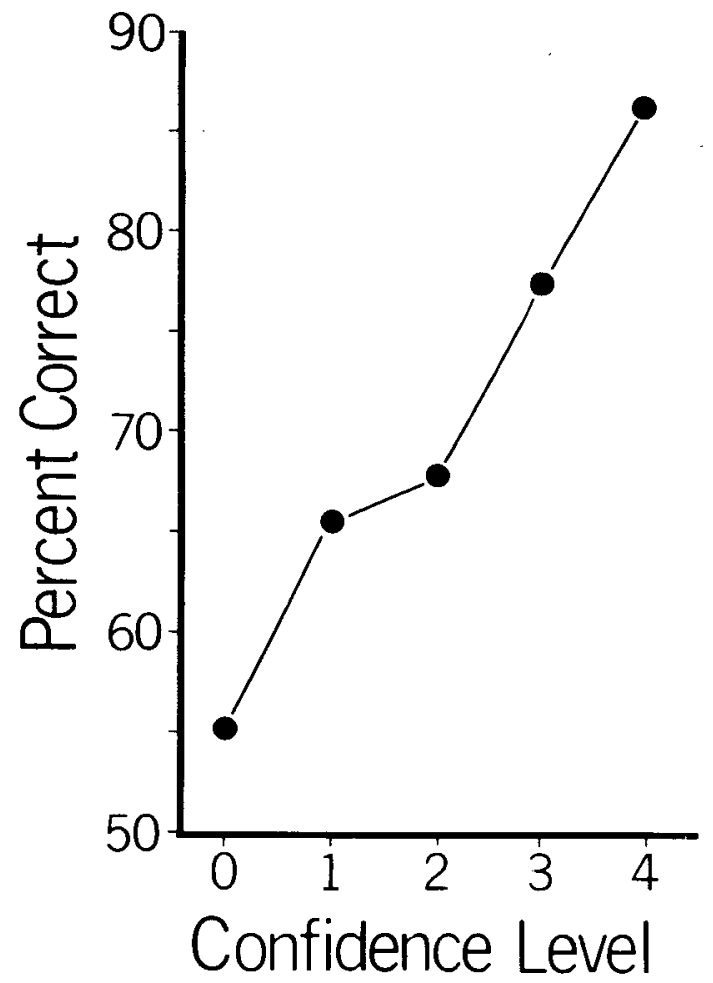

Figure 2. Mean correct identification of the sex of walkers as a function of confidence in the judgment.

clearly. If this walker is included, the pattern of results is still statistically reliable, though the mean decreases by about 10 points at each level of confidence. When not at all confident the raters' performance is not better than chance, $55 \%$ [t(29) = 1.0, n.s.]; when most confident, it is an impressive $87 \%[\mathrm{t}(29)=9.1, \mathrm{p}<.001]$. The linear trend is robust $[\mathrm{F}(1,90)=12.3, \mathrm{p}<.01]$, without higher order components. It suggests that the compelling nature of the general percept of a person walking (Johansson, 1973) is extended to judgments of the walker's sex. Remember, no feedback was given at any time during this or any other experiment in this paper. 


\section{EXPERIMENT 2: STATIC DISPLAYS}

It is clear that a dynamic display of point-lights is sufficient for recognizing the sex of a walker. Next, we sought to determine if similar static displays would do as well.

\section{Method}

Four photographs were taken of stopped images of each walker, as shown in Figure 1. All four comprised a set and were mounted on cardboard in the same arrangement as in the figure. Five photocopies were made of each set. Twenty different Wesleyan University undergraduates, 10 males and 10 females, performed two tasks: (a) each looked at one sheet and guessed what the point-light displays represented, and (b) after being told that the dots represented walkers, they sorted the 30 sheets $(6$ walkers, 5 copies of each set) into two piles, male and female. They were not told how many walkers were in the sample.

\section{Results and Discussion}

When first presented with the static displays, only one subject guessed that they represented people. The most common responses were that the pictures were constellations of stars or Christmas tree lights. Thus, the impression of a person walking in a static array is not compelling or immediate, although it is compelling and immediate in the Johansson dynamic-array experiments. Johansson's (1976) more recent work corroborates this result. He found that very brief presentations $(100 \mathrm{msec})$ of people walking or running were not identifiable as people, whereas longer presentations ( $\geqslant 200 \mathrm{msec}$ ) were.

When sorting the displays according to sex of walker, the subjects fared no better. They yielded an overall performance of only $46 \%$, slightly, but not significantly, less than chance $[\mathrm{t}(19)=1.6$, n.s.]. Intrawalker reliability was very low. In Table 1, performance on each of the six walkers in static presentation is shown against the data of Experiment 1 for dynamic presentation. All differences are $9 \%$ or greater and all are statistically reliable.

In summary, then, viewers can recognize the sex of a walker from a dynamic display without familiarity cues, but not from four static displays taken out of the dynamic sequence.

\section{EXPERIMENTS 3 AND 4: DYNAMIC DISPLAYS VARYING ARMSWING AND WALKING SPEED}

Next, we turned our efforts toward the discovery of cues for the judgment of a walker's sex. Our approach was to investigate why the sex of Walker 1 was misidentified, in the hope that general principles might arise. Inspection of the stimuli suggested two possibilities. First, the female walkers had more pronounced armswing than the males, as can be seen in Figure 1. Moreover, Walker 1 had the least armswing of the women. Second, the women in our sample (Walkers 1, 2, and 3) walked faster than the men $(4,5$, and 6$)$. We timed each walker during each pass across the monitor in the test tape used in Experiment 1 and found that they averaged $2.61,2.57$, $2.53,2.71,3.04$, and $2.75 \mathrm{sec}$ for Walkers 1 through 6 , respectively. Notice that the distributions of walking times do not overlap, and that Walker 1 is the slowest of the women. These two cues, armswing and walking speed, are correlated in natural gait. For example, the faster one walks the more one generally pumps his or her arms. Nevertheless, in Experiment 3 we isolated armswing as distinct from walking speed, and in Experiment 4 we attempted to isolate walking speed from armswing.

\section{Method}

Walkers 1, 2, 4, and 6 were brought back for another recording session. Thus, though our sample of walkers is smaller still, we retained two males and two females. For Experiment 3, five types of armswing were recorded: a "normal" armswing,' two smaller-than-normal armswings, and two larger-than-normal armswings. The smaller-than-normal armswings had the walkers (a) walk with their hands in the front pockets of their jeans, and (b) walk with hands at their sides using as little armswing as possible without stiffening the muscles of the upper body. The two larger-than-normal armswings were (a) just slightly larger than normal, and (b) very exaggerated, with the front arm (elbow to wrist) always reaching the horizontal with each stride. Large and exaggerated armswings were standardized simply through the judgments of the authors at the time of recording.

In Experiments 4, five walking speeds were recorded: the normal walking speed, two slower-than-normal speeds, and two fasterthan-normal speeds. The normal speed was determined by matching metronome pulses against the walker's pace. The pulse was varied until each walker declared that he or she was most comfortable walking at a particular rate. Slower speeds were 8 and 16 strides/min slower than the normal; faster speeds were 8 and 16 strides/min faster than normal. In all cases, the individuals walked with the beat of the metronome. The normal speeds for Walkers 1, 2, 4, and 6 were 104, 108, 104, and 96 paces $/ \mathrm{min}$, respectively.

Test tapes were recorded in the same manner as in Experiment 1, except that only two tokens of each walker were used in each condition and only left-to-right passes across the monitor screen were used. On each experimental tape, tokens were mixed and presented in a 40 -item sequence. As a group, 30 Wesleyan undergraduates (15 males and 15 females) were paid to view the video test tape for Experiment 3. As a group, 28 members of a psychology class (10 males and 18 females) viewed the sequence for Experiment 4. Each viewer wrote down $M$ or $F$ to indicate the sex of the walker for each trial. Confidence measures were also taken, but, since they revealed nothing different from the previous studies, they will not be discussed.

\section{Results and Discussion}

In Experiment 3, armswing had no clear effect on judgments except that nonnormal armswings tended to interfere with identifiability. When the individual walked with normal armswing, sex identification was comparable with that of previous experiments with this stimulus sample, $65 \%[\mathrm{t}(29)=4.1$, $\mathrm{p}<.001]$. With hands in pockets, walker's sex was only $46 \%$ identifiable; with hands at sides, it was only $54 \%$ identifiable, and for armswing very 
exaggerated, it was only $55 \%$ identifiable. None of these results differs significantly from chance. Only with armswings slightly larger than normal was the walker's sex identifiable at a rate greater than chance, $59 \%[\mathrm{t}(29)=2.6, \mathrm{p}<.01]$, but at a level reduced from that for normal armswing. Increasing armswing did not make walkers appear more feminine; nor did decreasing armswing make them appear more masculine. Summed across the five armswing conditions, the sex of each walker was correctly identified $33 \%, 66 \%, 54 \%$, and $70 \%$ for Walkers, 1, 2, 4, and 6, respecitvely. These percentages are comparable to those in Experiment 1 .

In Experiment 4, walking speed did have a small effect, as shown in Table 2. For the two men, the manipulation interfered with correct identification. That is, although the men were always identified as male from the dynamic display, conditions of both faster- and slower-than-normal impeded viewer performance. For the two women, on the other hand, increase in walking speed was associated with greater correct identification. This linear trend was statistically reliable $[F(1,10)=6.2, p<.05]$. However, the trend for males and females together is not significant.

Since these two studies were, in part, prompted by the results of our anomalous walker, Walker 1 , inspection of her results seemed warranted. Oddly enough, when walking with normal armswing or at normal speed she failed to be identified as either male or female, thus not entirely replicating her results from Experiment 1. Having her walk faster did make her appear somewhat feminine $(57 \%$ correct identification), but this effect was not statistically reliable.

\section{EXPERIMENT 5: DYNAMIC DISPLAYS WITH CERTAIN JOINTS NOT REPRESENTED}

The results of Experiments 3 and 4 suggest that more or less holistic aberrations of normal gait either have little influence on the viewer performance for these dynamic displays or actually impede viewer performance. In no case did either the manipulation of armswing or walking speed systematically improve

Table 2

Percent Correct Identification of Male and Female Walkers at Five Walking Speeds

\begin{tabular}{lccccc} 
& \multicolumn{5}{c}{ Walking Speed (strides/min } \\
& deviation from normal) \\
\cline { 2 - 6 } & -16 & -8 & 0 & +8 & +16 \\
\hline Female Walkers & 44 & $38^{*} \dagger$ & $57^{*}$ & $57^{*}$ & $66^{*}$ \\
Male Walkers & $69^{*}$ & $77^{*}$ & $78^{*}$ & $65^{*}$ & $70^{*}$ \\
Mean & 56 & 57 & $67^{*}$ & $61^{*}$ & $68^{*}$ \\
\hline
\end{tabular}

${ }^{*} p<.05$, two-tailed $t$ test.

tSignificant and in the opposite direction. the identifiability of all walkers' sex. In Experiment 5 , we examine information in the normal gait, but with less displayed to the viewer. Our hope was to determine the locus of information important to the viewer. In other words, which joints are necessary for the identification of a walker's sex, and which, if any, are sufficient?

\section{Method}

Walkers 1, 2, 4, and 6 were employed again. Source videotapes were recorded for this experiment at the same time as those for Experiments 3 and 4.

Seven configurations of lights were used for each walker. For notational purposes, we will designate the shoulder as $S$, the elbows $E$, the wrists $R$, the hip $H$, and knees $N$, and the ankles $A$. Three configurations included information only about the lower body-A, HA (hip and ankles), and HNA (for hip, knees, and ankles). ${ }^{2}$ Two others contained information only about the upper body-SER (for shoulder, elbows, and wrists) and SERH (shoulder, elbows, wrists, and hip). A sixth configuration portrayed information about all joints except the knees (SERHA), and a seventh included all joints (SERHNA).

The preparation of the test tape was identical to that in Experiments 3 and 4 . All token types were blocked by configuration. The test tape began with six practice trials of Walkers 3 and 5 with lights on all joints, followed by a random sequence of $A$ (ankles alone), then random sequences of SER, HA, SERH, HNA, SERHA, and SERHNA, in that order. Due to an error made during the recording session, all tokens of Walker 1 in $A$, $H A$, and HNA configurations were lost.

As a group, members of an introductory psychology class viewed the test sequence. There were 132 males and 127 females, for a total of 259 viewers. They watched the sequence on one of two monitors placed at the front of a lecture hall. Visual angle for viewers was between about $0^{\circ} 20^{\prime}$ and $3^{\circ} 0^{\prime}$. Each viewer wrote down $\mathrm{M}$ or $\mathrm{F}$ to indicate the sex of the walker.

\section{Results and Discussion}

Overall, the viewers could identify the sex of the walkers $63 \%$ of the time $[t(258)=10.2, p<.001]$. In each of the separate conditions, the viewers were able to identify the walkers correctly (see the last column of Table 3 ). Correlated t tests revealed that, on the average, upper-body and full-body conditions were significantly more identifiable than lower-body conditions (all ps $<.01)^{3}$ : Armswing information, as suggested by the results of Experiment 3, appears to be especially helpful. There were no significant differences among lower-body conditions: Adding hips and knees to ankles did not increase accuracy of guessing. However, adding to upper body information (SER) any information about the lower body (SERH, SERHA, and SERHNA) significantly increased accuracy (ps $<.01$ ). It appears that, roughly speaking, any joint is sufficient and no joint is necessary for the recognition of a walker's sex.

Interestingly, Walker 1, the formerly anomalous subject of Experiment 1, became identifiable as a female (although in her SER condition she is the only walker not different from chance). Perhaps her walk when viewed from her right side is reliably more "feminine" than when viewed from her left side. (Both were used in Experiment 1, but only the former 
Table 3

Percent Correct Identification of Sex of Walker for Each of Seven Dynamic Point-Light Configurations

\begin{tabular}{|c|c|c|c|c|c|c|}
\hline \multirow[b]{2}{*}{ Body Portion } & & \multicolumn{2}{|c|}{$\begin{array}{c}\text { Female } \\
\text { Walkers }\end{array}$} & \multicolumn{2}{|c|}{$\begin{array}{c}\text { Male } \\
\text { Walkers }\end{array}$} & \multirow[b]{2}{*}{ Mean } \\
\hline & & 1 & 2 & 4 & 6 & \\
\hline Lower Body & $\begin{array}{l}\text { A } \\
\text { HA } \\
\text { HNA }\end{array}$ & & $\begin{array}{l}61^{*} \\
59^{*} \\
62^{*}\end{array}$ & $\begin{array}{l}60^{*} \\
55^{*} \\
42^{* \dagger}\end{array}$ & $\begin{array}{l}39^{*} \dagger \\
55 \\
62 *\end{array}$ & $\begin{array}{l}54^{*} \\
56^{*} \\
55^{*}\end{array}$ \\
\hline Upper Body & $\begin{array}{l}\text { SER } \\
\text { SERH }\end{array}$ & $\begin{array}{l}53 \\
59 *\end{array}$ & $\begin{array}{l}62^{*} \\
69^{*}\end{array}$ & $\begin{array}{l}65^{*} \\
69^{*}\end{array}$ & $\begin{array}{l}65^{*} \\
84^{*}\end{array}$ & $\begin{array}{l}61^{*} \\
70^{*}\end{array}$ \\
\hline Full Body & $\begin{array}{l}\text { SERHA } \\
\text { SERHNA }\end{array}$ & $\begin{array}{l}59^{*} \\
60^{*}\end{array}$ & $\begin{array}{l}72 * \\
77 *\end{array}$ & $\begin{array}{l}66^{*} \\
67^{*}\end{array}$ & $\begin{array}{l}72^{*} \\
78^{*}\end{array}$ & $\begin{array}{l}67^{*} \\
70^{*}\end{array}$ \\
\hline Mean & & $58 *$ & $66^{*}$ & $60^{*}$ & $65^{*}$ & \\
\hline
\end{tabular}

Note $-S=$ shoulder, $E=$ elbows, $R=$ wrists, $H=$ hip, $N=$ knees, $A=$ ankles.

${ }^{*} p<.05$, two-tailed $t$ test.

tThese results are in the opposite direction.

in Experiments 3, 4, and 5.) In addition, since the recording session for the last three experiments occurred at a different time from that for the first study, her mood, her walking speed, or even the exact location of the reflectant tape might have changed enough to cause these effects. Other anomalies in these data, that Walker 6's ankles and Walker 4's legs appear feminine, are perhaps best attributable to the particular sequence of trials. Given the state of our knowledge, we believe that it is uninteresting and unrewarding to try to develop an ideographic approach to the study of gait. Therefore, such reversals in the data will not be discussed further. Only the nomothetic trends are considered.

Since the study was conducted in a large lecture hall and the visual angle of the stimuli varied from $3^{\circ} 0^{\prime}$ to $0^{\circ} 20^{\prime}$ for the observers, we decided to evaluate the accuracy of guesses as a function of distance from the stimuli. The rows of seats were divided into three sections: near, halfway, and far. Guessing for these groups was, respectively, $65 \%, 62 \%$, and $61 \%$ correct [linear trend, $F(1,219)=5.49, p<.02$ ]. It is noteworthy that even the far group was well above chance in the estimation of the sex of the walkers.

\section{GENERAL DISCUSSION AND SUMMARY}

The point of this investigation was not to study sex. We are not interested in why males and females walk differently, whether through socialization or through biomechanical differences. Instead, we have used sex as a convenient, pervasive, and abstract source of structural information. Shaw, McIntyre, and Mace (1974) argue that a successful study of event must consider two issues: the underlying dynamic aspect of the event, or the transformational invariant, and the underlying unity of the structures involved, or the structural invariant. Walking, of course, is our transformational invariant, and sex part of the structural invariant.

In Experiment 1 we confirm the suspicions of Maas and Johansson. That is, viewers can recognize the sex of a walker from a dynamic point-light display. Given information about the shoulder, elbows, wrists, hip, knees, and ankles, recognition appears to hover around $70 \%$. Experiment $2 \mathrm{em}-$ phasizes that it is the dynamic nature of the display which is important: Recognition of the sex of a walker is simply not possible from four static arrays taken from the dynamic sequence.

In Experiments 3 and 4, we demonstrated that there is a certain "grammar" to an individual's natural walk and that violation of it decreases the identifiability of the sex of the walker. Change in movement of the hands and arms during walking detracts from the overall strength and integrity of the percept. In other words, we violated the nature of the transformational invariant to some small degree. Deviation in the walker's speed from that which is normal also disrupts the transformational invariant, although in a less clear fashion.

In Experiment 5, we found, essentially, that no clue is necessary for identification. It would appear that any light on joints of the upper body or any of the lower body may be absent. Moreover, it appears that any cue is sufficient. Most surprising to us was that ankles alone yielded greater-than-chance performance. We anticipated that the hip would be particularly important. By itself, it proved not to be, but in conjunction with information from the upper body it enhances the percept.

Viewers immediately recognize the pendular motion of a few lights as a person walking. No feedback is required, not even for them to make reasonably accurate guesses as to the sex of the walker. Walking appears to be a holistic act. Information as abstract as the sex of the walker appears to be distributed through all the movement.

\section{REFERENCES}

Cutting, J. E., \& Kozlowski, L. T. Recognizing friends by their walk: Gait perception without familiarity cues. Bulletin of the Psychonomic Society, 1977, 9, 353-356.

Johansson, G. Visual perception of biological motion and a model for its analysis. Perception \& Psychophysics, 1973, 14, 201-211.

Johansson, G. Projective transformations as determining visual space perception. In R. B. MacLeod \& H. L. Pick (Eds.), Perception: Essays in honor of J. J. Gibson. Ithaca, N.Y: Cornell University Press, 1974.

Johansson, G. Visual motion perception. Scientific American, 1975, 232(6), 76-89.

Johansson, G. Spatio-temporal differentiation and integration in visual motion perception. Psychological Research, 1976, 38. 379-393.

MaAs, J. B., \& Johansson, G. Motion perception I: 2-dimensional motion perception. Boston: Houghton Mifflin, 1971 (film). (a) 
MaAs, J. B., \& Johansson, G. Motion perception II: 3-dimensional motion perception. Boston: Houghton Mifflin, 1971 (film). (b)

Shaw, R. E.. MCINTYRe, M., \& Mace, W. M. The role of symmetry in event perception. In R. B. MacLeod \& H. L. Pick (Eds.), Perception: Essays in honor of J. J. Gibson. Ithaca, N.Y: Cornell University Press, 1974.

\section{NOTES}

1. People differ greatly in the amount they swing their arms when they walk. Moreover, it is not uncommon to discover considerable asymmetries: A given individual may swing one arm through $60^{\circ}$ of an arc while holding the other arm almost motionless. Our six walkers appeared to have symmetrical walks and armswings, and we did not coach them to make their walks "more normal." Nonetheless, the data of these experiments when taken together hint at the possibility of asymmetries for Walker 1 .

2. Strictly speaking, the HA and HNA conditions do give some upper body information. Even though no tape was mounted on the arm, it still occluded the reflectant patch at the waist during part of every stride. The occlusion gives some information about the velocity of the pendular movement of the arm, and thus some information about movement in the torso.

3. For these comparisons, the means of Walkers 2,4 , and 6 were used.

(Received for publication February 14, 1977; revision accepted April 4, 1977.) 